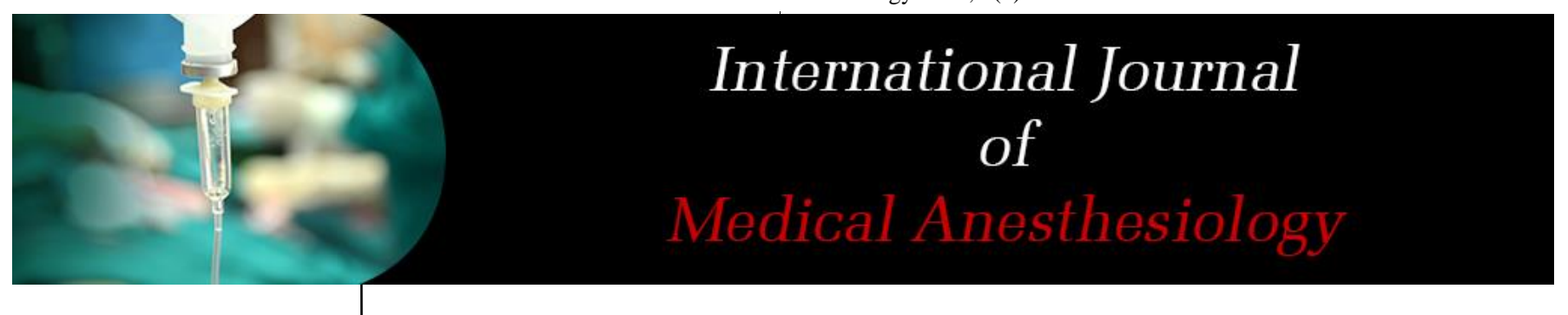

E-ISSN: 2664-3774

P-ISSN: 2664-3766

www.anesthesiologypaper.com

IJMA 2020; 3(1): 264-267

Received: 14-11-2019

Accepted: 18-12-2019

Dr. Parthibhan

Assistant Professor,

Department of Anaesthesia

Madha Medical College \&

Hospital Kundrathur Main

Road, Kovur, Thandalam.

Chennai, India
Corresponding Author: Dr. Parthibhan Assistant Professor, Department of Anaesthesia Madha Medical College \& Hospital Kundrathur Main Road, Kovur, Thandalam. Chennai, India

\section{Comparative study of haemodynamic stability of Propofol versus Etomidate during Endoscopic Retrograde Cholangio pancreatography}

\section{Dr. Parthibhan}

DOI: https://doi.org/10.33545/26643766.2020.v3.i1d.101

\begin{abstract}
Background: Endoscopic procedures like ERCP are performed with patient under moderate sedation. Recently sedation with etomidate and propofol was compared for colonoscopy. EtomidateRemifentanil administration for sedation and analgesia during colonoscopy resulted in more stable haemodynamic responses and shorter recovery and discharge time. So the purpose of the study was to compare study of haemodynamic stability of propofol versus etomidate during Endoscopic Retrograde Cholangiopancreatography.

Material and Methods: Patients were divided for sedation into 2 groups - etomidate and propofol. Haemodynamic response to induction agent etomidate or propofol by measuring the systolic pressure, diastolic pressure, mean arterial pressure and heart rate starting from baseline values followed by measuring the same at serial intervals during the procedure. Results were analysed in both groups Results: It was found that the average time from stoppage of sedation to the time to reach a Ramsay sedation score of lesser than 3 was higher in the patients receiving propofol. The mean time of recovery was 8.68 minutes for propofol and $6.28 \mathrm{~min}$ for etomidate; this was found to be statis tically significant, with a $\mathrm{p}$ value $<0.05$. Conclusion: our study shows that etomidate as an agent for procedural sedation during ERCP caused more stable haemodynamics compared to propofol, Thus we conclude that etomidate is a good sedative agent for ERCP in ASA I - III patients.
\end{abstract}

Keywords: Assess refers to process of the critical analysis and valuation and judgement of the status or quality regarding prevention and home care management of chickenpox in children

\section{Introduction}

Endoscopic procedures like ERCP are performed with patient under moderate sedation, a technique known as conscious sedation which is defined by the American Society of Anaesthesiologists as a drug-induced depression of consciousness during which patients respond purposefully to verbal commands, either alone or accompanied by light tactile stimulation ${ }^{[1]}$. It aims at reducing patient anxiety, discomfort and pain and enhancing patient co-operation and facilitating the performance or the endoscopist. Adequate patient sedation is mandatory for most interventional endoscopic procedures. Historically, hepatopancreatobiliary surgeons and gastroenterologists have performed endoscopic retrograde cholangiopancreatography (ERCP) using benzodiazepine sedation ${ }^{[2]}$. This is poorly tolerated by a substantial number of patients, which leads to its potential premature abandonment and subsequent additional investigations and therapeutics, and hence to the exposure of patients to avoidable risk and the health service to increased costs.

Over the last few years, there has been growing interest in the use of propofol in endoscopy. ERCP is an uncomfortable procedure that needs sedation. However, propofol may lead to deep sedation or even dangerous adverse events that require cardiopulmonary support (2). Although propofol sedation seems a promising strategy during ERCP, its side effects should never be underestimated [3]. With respect to its potential side effects, the administrator should be aware of the risk of hypotension and respiratory depression.

Most patients undergoing ERCP have obstructive jaundice due to malignant or benign disease. Such patients are prone to hypotension and bradycardia during conscious sedation. Propofol induction results in hypotension, respiratory depression and loss of protective reflexes (3). 
There have been studies conducted on the usage of etomidate for procedural sedation in the emergency department and it was found that that Etomidate is an appropriate and valuable agent for performing procedural sedation in the ER ${ }^{[4]}$. With a rapid onset and recovery time and relative lack of significant haemodynamic and respiratory effects the sedation provided by etomidate was safe for procedures in the emergency department. Patients with obstructive jaundice have decreased sensitivity to both the sympathetic and vagal component of the baroreflex ${ }^{[5]}$. There is also an increased risk of hypotension and bradycardia in patients with obstructive jaundice, in such a patient a more haemodynamically stable sedative agent would be preferable. This is especially significant in elderly patients of patients with higher ASA physical status, in whom an alternative sedative agent should be considered ${ }^{[6]}$. Etomidate, being a haemodynamically stable I.V agent may provide a safe alternative for sedation during ERCP.

Recently sedation with etomidate and propofol was compared for colonoscopy. Etomidate-remifentanil administration for sedation and analgesia during colonoscopy resulted in more stable haemodynamic responses and shorter recovery and discharge times ${ }^{[7]}$.

So the purpose of the study was to compare study of haemodynamic stability of propofol versus etomidate during Endoscopic Retrograde Cholangiopancreatography

\section{Material and Methods}

The study is a prospective study with data collection using verbal interview and proforma. The study will be a randomized, single-blinded, comparative study. The present study will be carried out at the department of anaesthesiology, Apollo Hospital, Greams Road, Chennai. 600 bed multispecialty, tertiary care, urban hospital with 14200 out-patient and 1930 admissions annually. Study was done between August 2016 to August 2017 after approval of all the study protocols by the ethical committee of Apollo Hospital. All patients will be informed and consented before entry into the study.

Patients admitted in Apollo Hospital for undergoing ERCP for standard clinical indications, satisfying the inclusion criteria and willing to participate in the study.

One of our primary objectives is to compare the periprocedural mean arterial pressures for patients receiving Etomidate or Propofol for procedural sedation.

Patient with ASA I, II and III \& undergoing ERCP for standard clinical indications such as Choledocholithiasis, Bile duct leak, Biliary obstruction. Patients greater than 18 years of age and less than 80 years of age were included in the study. Patient with known allergy to one of the study drugs Ejection fraction low $(<40 \%)$, severe respiratory disease (room air sat $<90 \%$ ), anticipated difficult airway were excluded in the study.

Patients were divided for sedation into 2 groups - etomidate and propofol. Odd numbered cases were placed into group
E: etomidate and even numbered cases were placed into group P: propofol. Once patient was inside the operating room, standard monitors were connected and baseline parameters were recorded: $\mathrm{BP}$, heart rate, $\mathrm{SpO} 2$ were recorded.

In group A, etomidate was delivered at a dose of $30 \mu \mathrm{g} \bullet \mathrm{kg}$ 1 , then ERCP was started. Anaesthesia maintained with etomidate $(8-12 \mu \mathrm{g} \bullet \mathrm{kg}-1 \bullet \mathrm{min}-1)$ during ERCP.

Group B: The propofol group, propofol was delivered at a dose of $0.3 \mathrm{mg} \cdot \mathrm{kg}-1$, and anaesthesia maintained with propofol $(0.12-0.18 \mathrm{mg} \bullet \mathrm{kg}-1 \bullet \mathrm{min}-1)$. The time for recovery from sedation which is defined as the time from stoppage of the infusion to the time till reaching a Ramsay score $<3$ was recorded. Patient satisfaction with the procedure was assessed 1 hour after the procedure.

Haemodynamic response to induction agent etomidate or propofol by measuring the systolic pressure, diastolic pressure, mean arterial pressure and heart rate starting from baseline values followed by measuring the same at serial intervals during the procedure. Data analysis was carried out by SPSS, Version 16.0. All ' $P$ ' values $<0.05$ will be considered statistically significant. Results were analysed in both groups based on various parameters such as sex, presence or absence of coexisting diseases: diabetes, hypertension, ASA classification, occurrence of complications: hypoxia, hypotension, nausea, pain on injection, sedation score and time of recovery. Patient satisfaction was also noted. The trend in haemodynamic parameters was analysed.

\section{Observations \& Results}

Out of 80 patients, 63 patients were male, $47.6 \%$ of the males were in propofol group and $52.4 \%$ were in etomidate group. 17 patients were female, $58.8 \%$ were in propofol group and $41.2 \%$ were in etomidate group. Both groups were comparable with respect to sex distribution as there was no statistically significant difference ( $p$ value- 0.412 , more than 0.05) in sex distribution between the two groups. The sedation was assessed using Ramsay's sedation score, with a score of 1 denoting an anxious/restless patient and a score of greater than 4 denoting sedated patient. A sedation score of 5 was the required level for the procedure. A sedation score of 5 denoting sluggish response to stimulus was achieved in $100 \%$ of the patients from propofol group. $2.5 \%$ of patients from etomidate group were found to have a score of 4 and $97.5 \%$ of patients had a sedation score of $5 . \mathrm{P}$ value was 1.00

Haemodynamic response was studied as a change in systolic, diastolic pressure and mean arterial pressure was noted and the trend was analysed by recording the vitals at 3 mins, 5 mins, 10 mins, 20 mins and 30 mins after induction. The heart rate and saturation were also noted at these times. The change in systolic blood pressure was plotted as follows: 
Table 1: Difference in SBP between the groups

\begin{tabular}{|c|c|c|c|c|c|c|c|}
\hline & Group & $\mathbf{N}$ & Mean & Std. Deviation & Std. Error Mean & Levines's test for equality of variances: $t$ & p value \\
\hline \multirow{2}{*}{ SBP T0 } & Propofol & 40 & 135.58 & 22.031 & 3.483 & \multirow[t]{2}{*}{ - } & \multirow{2}{*}{.705} \\
\hline & Etomidate & 40 & 133.80 & 19.684 & 3.112 & & \\
\hline \multirow{2}{*}{ SBP T1 } & Propofol & 40 & 124.28 & 24.829 & 3.926 & \multirow{2}{*}{-2.255} & \multirow{2}{*}{.027} \\
\hline & Etomidate & 40 & 135.22 & 18.077 & 2.858 & & \\
\hline \multirow{2}{*}{ SBP T2 } & Propofol & 40 & 122.58 & 20.046 & 3.170 & \multirow{2}{*}{-3.200} & \multirow{2}{*}{.002} \\
\hline & Etomidate & 40 & 136.32 & 18.346 & 2.901 & & \\
\hline \multirow{2}{*}{ SBP T3 } & Propofol & 40 & 122.02 & 16.862 & 2.666 & \multirow{2}{*}{-3.547} & \multirow{2}{*}{.001} \\
\hline & Etomidate & 40 & 137.48 & 21.783 & 3.444 & & \\
\hline \multirow{2}{*}{ SBP T4 } & Propofol & 40 & 119.65 & 18.455 & 2.918 & \multirow{2}{*}{-4.659} & \multirow{2}{*}{.000} \\
\hline & Etomidate & 40 & 139.15 & 18.974 & 3.000 & & \\
\hline \multirow{2}{*}{ SBP T5 } & Propofol & 40 & 118.92 & 16.257 & 2.570 & \multirow{2}{*}{-5.238} & \multirow{2}{*}{.000} \\
\hline & Etomidate & 40 & 141.00 & 21.122 & 3.340 & & \\
\hline
\end{tabular}

The baseline systolic BP at T0 was comparable for both the groups, as denoted by a p value of 0.380 and as seen in the graph. The systolic BP taken 3 minutes after administration of propofol or etomidate (T1) and at 5 minutes after administration showed a significant difference, propofol having a fall in mean SBP from $135 \mathrm{~mm} \mathrm{Hg}$ to $124 \mathrm{~mm} \mathrm{Hg}$.
This was not found in the etomidate group and the $\mathrm{p}$ value was found to be significant, $\mathrm{p}$ for SBP T1 being 0.027 and for $\mathrm{T} 2 \mathrm{p}=0.002$. This trend continued till 30 minutes after induction. The etomidate group showed a tendency to a higher systolic blood pressure with a mean SBP of $141 \mathrm{~mm}$ $\mathrm{Hg}$ at 30 minutes after induction.

Table 2: Difference in DBP between the groups

\begin{tabular}{|c|c|c|c|c|c|c|c|}
\hline & Group & $\mathbf{N}$ & Mean & Std. Deviation & Std. Error Mean & Levines's test for equality of variances: $t$ & p value \\
\hline \multirow{2}{*}{ DBP T0 } & Propofol & 40 & 80.32 & 15.786 & 2.496 & \multirow[t]{2}{*}{ 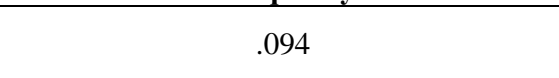 } & \multirow{2}{*}{.925} \\
\hline & Etomidate & 40 & 80.05 & 9.682 & 1.531 & & \\
\hline \multirow{2}{*}{ DBP T1 } & Propofol & 40 & 72.62 & 15.029 & 2.376 & \multirow{2}{*}{-3.815} & \multirow{2}{*}{.000} \\
\hline & Etomidate & 40 & 82.88 & 7.933 & 1.254 & & \\
\hline \multirow{2}{*}{ DBP T2 } & Propofol & 40 & 76.25 & 13.469 & 2.130 & \multirow{2}{*}{-2.762} & \multirow{2}{*}{.007} \\
\hline & Etomidate & 40 & 83.55 & 9.897 & 1.565 & & \\
\hline \multirow{2}{*}{ DBP T3 } & Propofol & 40 & 77.12 & 15.324 & 2.423 & \multirow{2}{*}{-2.565} & \multirow{2}{*}{.012} \\
\hline & Etomidate & 40 & 84.50 & 9.795 & 1.549 & & \\
\hline \multirow{2}{*}{ DBP T4 } & Propofol & 40 & 71.50 & 14.093 & 2.228 & \multirow{2}{*}{-5.968} & \multirow{2}{*}{.000} \\
\hline & Etomidate & 40 & 85.68 & 8.960 & 1.417 & & \\
\hline \multirow{2}{*}{ DBP T5 } & Propofol & 40 & 72.80 & 11.371 & 1.798 & \multirow{2}{*}{-5.121} & \multirow{2}{*}{.000} \\
\hline & Etomidate & 40 & 85.95 & 11.598 & 1.834 & & \\
\hline
\end{tabular}

The baseline diastolic BP was comparable for both groups, with a $\mathrm{p}$ value of 0.925 . The diastolic BP measured at T1 and T2 showed a significant fall in the propofol group as compared to the etomidate group, with propofol having a fall in the mean diastolic BP from $80.32 \mathrm{~mm} \mathrm{Hg}$ to 72.62 $\mathrm{mmHg}$ at $\mathrm{T} 1$ and $76.25 \mathrm{~mm} \mathrm{Hg}$ at $\mathrm{T} 2$. This trend continued for the duration of the study which was 30 minutes. The fall in diastolic BP after induction was not found in patients receiving etomidate, the mean DBP being $80.05 \mathrm{~mm} \mathrm{Hg}$ at $\mathrm{T} 0,82.88 \mathrm{mmHg}$ at $\mathrm{T} 1$ and stayed within this range. The $\mathrm{p}$ value for DBP at T1 to T5 was found to imply a significant difference between the 2 groups, T1 being $\mathrm{p}=0.000$ and so on.

The mean arterial pressure for both groups at $\mathrm{T} 0$ (baseline) was comparable. A fall in MAP was seen in the patients receiving propofol (from a mean MAP of $92 \mathrm{mmHg}$ to a mean MAP of $86 \mathrm{~mm} \mathrm{Hg} 5$ minutes after induction). This fall was not seen with etomidate, the $\mathrm{p}$ value was found to be significant, $p<0.05$.

It was found that the average time from stoppage of sedation to the time to reach a Ramsay sedation score of lesser than 3 was higher in the patients receiving propofol. The mean time of recovery was 8.68 minutes for propofol and 6.28 min for etomidate; this was found to be statistically significant, with a $\mathrm{p}$ value $<0.05$.

\section{Discussion}

ERCP is an uncomfortable procedure and it has been known that the procedure requires sedation. Sedation is also preferred due to the complexity of the procedure and the lengthy duration. A lot of sedative agents have been used for this purpose and propofol is the agent generally preferred due to its good hypnotic action, rapid onset and recovery with minimal side effects. It was reported by Fanti L et al. that sedation with propofol was safe and fully effective(49). However it was found that transient hypotension and transient hypoxia occurred in around $7 \%$ of the patients receiving propofol ${ }^{[10,11]}$.

Most patients undergoing ERCP suffer from obstructive jaundice. Hypotension and bradycardia has been found to occur more commonly in patients with obstructive jaundice, as described by one study ${ }^{[12]}$. They also state that these patients have a decreased sensitivity to both vagal and sympathetic components of the baroreflex. Despite being safe, it was suggested that an alternative agent other than propofol should be considered for these patients.

In our study, the haemodynamic parameters were stable in the etomidate group. Hypotension occurred in the propofol group. Propofol has been found to have risk of haemodynamic adverse events requiring the use of vasopressors,

This has been noted in multiple studies for various procedures such as in the Emergency Room [13] and for sedation during colonoscopy ${ }^{[14]}$. These findings correlate with the findings in our study, there was a significant difference between the 2 groups, with propofol having a fall 
in systolic, diastolic and mean arterial pressure after induction. These findings also correspond to the findings reported who concluded that etomidate sedation resulted in more stable haemodynamics than propofol.

A limitation of our study was that we did not measure the plasma cortisol or adrenocorticotrophic hormone levels after administration of etomidate. Adrenocortical suppression is a known complication of etomidate. However, in a systemic review and meta-analysis of randomized controlled trials and observational study, it was stated that a single-dose etomidate does not increase mortality in patients with sepsis ${ }^{[16]}$. It was also reported by Wagner et al. that there was no evidence of hypotension, or longer hospital stay or greater mortality after a single dose of etomidate or after a short infusion.

In conclusion our study shows that etomidate as an agent for procedural sedation during ERCP caused more stable haemodynamics compared to propofol, Thus we conclude that etomidate is a good sedative agent for ERCP in ASA I III patients.

\section{References}

1. Faigel DO, Baron TH, Goldstein JL, Hirota WK, Jacobson BC et al. Guidelines for the use of deep sedation and anesthesia for GI endoscopy. Gastrointest Endosc. 2002; 56:613-617.

2. Lichtenstein DR, Jagannath S, Baron TH, Anderson MA, Banerjee S, Dominitz JA et al. Sedation and anesthesia in GI endoscopy. Gastrointest Endosc. 2008; 68(5):815-826.

3. Demiraran Y, Tamer KE, Ilknur Y, Buket K, Gulbin S. The comparison of dexmedetomidine and midazolam used for sedation of patients under upper endoscopy:a prospective randomized study. Can J Gastroenterol. 2007; 21:25-29.

4. Carollo DS, Nossaman BD, Ramadhyani U. Dexmedetomidine:a review of clinical applications. Curr Opin Anaesthesiol. 2008; 21:457. Jain, Gupta and Jethava / Indian Journal of Clinical Anaesthesia. 2019; 6(4):587-591, 591-461.

5. Roback MG, Wathen JE, Bajaj L, Bothner JP. Adverse events associated eith procedural sedation and analgesia in a pediatric emergency department:a comparison of parenteral drugs. Acad Emerg Med. 2005; 12:508-513.

6. Paris A, Tonner PH. Dexmedetomidine in anesthesia. Curr Opin Anaesthsiol, 2005, 18-412.

7. Davis PJ, Cook DR. Clinical pharmacokinetics of the newer intravenous anaesthetic agents. Clin Pharmacokinet. 1986; 11:18-35.

8. Cote GA, Hovis RM, Ansstas MA, Waldbaum L, Azar $\mathrm{RR}$, et al. Incidence of sedation-related complications with propofol use during advanced endoscopic procedures. Clin Gastroen Hepatol. 2010; 8:137-142.

9. Angsuwatcharakon P, Rerknimitr R, Ridtitid W, Kongkam P, Poonyathawon S et al. Cocktail sedation containing propofol versus conventional sedation for ERCP: a prospective, randomized controlled study. BMC Anesthesiol. 2012; 9:12-20.

10. Song JC, Lu ZJ, Jiao YF. Etomidate Anesthesia during ERCP caused more stable haemodynamic responses compared with Propofol: A randomized clinical trial. Int J Med Sci. 2015; 12(7):559-565.

11. Aouad MT, Moussa AR, Dagher CM. Addition of ketamine tp propofol for initiation of procedural anesthesia in children reduces propofol consumption and preserves hemodynamic stability. Acta Anaesthesiol Scand. 2008; 52:561-565.

12. Fanti L, Agostoni M, Casati A, Guslandi M, Giollo P, et al. Targetcontrolled propofol infusion during monitord anesthesia in patients undergoing ERCP. Gastrointest Endosc. 2004; 60:361-366.

13. Lichtenstein DR, Jagannath S, Baron TH, Anderson MA, Banerjee $\mathrm{S}$ et al. Standards of practice committe of the American society for Gastrointestinal Endoscopy, Sedation and anesthesia in GI endoscopy. Gastrointest Endosc. 2008; 68:815-826.

14. Reves JG. Intravenous Anesthetics. In Miller Rd, ed. Miller's Anesthesia. 7th ed.Phildelphia:Elsevier Churchill Livingstone, 2009.

15. Ebert TJ, Muzi M, Berens R, Goff D, Kampine JP. Sympathetic responses to induction of anesthesia in humans with propofol or etomidate. Anesthesiol. 1992; 76:725-733.

16. Yang LQ, Song JC, Irwin MG, Song JG, Sun YM et al. Aclinical prospective comparison of anesthetics sensitivity and hemodynamic effect among patients with or without obstructive jaundice. Acta Anaesthesiol Scand. 2010; 54:871-877. 